\title{
Auditory difficulties in blast-exposed Veterans with clinically normal hearing
}

\author{
Gabrielle H. Saunders, PhD; $;^{1-2 *}$ Melissa T. Frederick, AuD; ${ }^{1}$ Michelle Arnold, AuD; ${ }^{3-4}$ ShienPei Silverman; $^{1}$ \\ Theresa H. Chisolm, PhD; ${ }^{3}$ Paula Myers, $\mathbf{P h D}^{\mathbf{4}}$ \\ ${ }^{1}$ National Center for Rehabilitative Auditory Research, Department of Veterans Affairs Portland Health Care System, \\ Portland, OR; ${ }^{2}$ Department of Otolaryngology, Oregon Health and Science University, Portland, OR; ${ }^{3}$ Department of \\ Communication Sciences and Disorders, University of South Florida, FL; ${ }^{4}$ James A. Haley Veterans' Hospital, Tampa, FL
}

\begin{abstract}
Vast numbers of blast-injured Operation Iraqi Freedom/Operation Enduring Freedom/Operation New Dawn personnel report postconcussive symptoms that include headache, dizziness, poor memory, and difficulty concentrating. In addition, many report hearing problems, such as difficulty understanding speech in noise, yet have no measureable peripheral auditory deficits. In this article, self-report and performancebased measures were used to assess 99 blast-exposed Veterans. All participants reported auditory problems in difficult listening situations but had clinically normal hearing. Participants' scores on self-report questionnaires of auditory difficulties were more similar to scores of older individuals with hearing impairment than to those of younger individuals with normal hearing. Participants showed deficits relative to published normative data on a number of performance-based tests that have demonstrated sensitivity to auditory processing deficits. There were several measures on which more than the expected number of participants (15.9\%) performed one or more standard deviations below the mean. These were assessments of speech understanding in noise, binaural processing, temporal resolution, and speech segregation. Performance was not universally poor, with approximately $53 \%$ of participants performing abnormally on between 3 and 6 of the 10 measures. We concluded that participants exhibited task-specific deficits that add to the evidence suggesting that blast injury results in damage to the central auditory system.
\end{abstract}

Clinical Trial Registration: ClinicalTrials.gov; Approaches to Auditory Rehabilitation for Mild Traumatic Brain Injury (mTBI); NCT00930774; https://clinicaltrials.gov/ct2/show/ $\underline{\text { NCT00930774?term }=\text { NCT00930774\&rank }=1}$
Key words: auditory processing disorder, blast injuries, central auditory dysfunction, combat disorders, hearing, hearing loss, mild traumatic brain injury, rehabilitation, traumatic brain injury, Veterans, Veterans health.

Abbreviations: 4F-PTA = four-frequency pure tone average; $\mathrm{AC}=$ across-channel; ATTR $=$ Adaptive Tests of Temporal Resolution; DS = Digit Span Test; FHQ = Functional Hearing Questionnaire; HINT $=$ Hearing in Noise Test; HL = hearing level; LC = left competing; LNC = left noncompeting; NA LiSN-S = North American Listening in Spatialized NoiseSentence Test; OEF = Operation Enduring Freedom; OIF = Operation Iraqi Freedom; OND = Operation New Dawn; $\mathrm{PTSD}=$ posttraumatic stress disorder; $\mathrm{RC}=$ right competing; $\mathrm{RCT}=$ randomized controlled trial; $\mathrm{RNC}=$ right noncompeting; $\mathrm{SD}=$ standard deviation; $\mathrm{SL}=$ sensation level; $\mathrm{SNR}=$ signal to noise ratio; $\mathrm{SPL}=$ sound pressure level; $\mathrm{SRTN}=$ speech reception threshold in noise; SSQ = Speech, Spatial, and Qualities; SSW = Staggered Spondaic Word Test; TBI = traumatic brain injury; TCST $=$ Time Compressed Speech Test; VA = Department of Veterans Affairs; WAIS-III = Wechsler Adult Intelligence Scale-3rd edition; WJ-III = Woodcock Johnson Tests of Achievement-III; WC = within-channel.

*Address all correspondence to Gabrielle H. Saunders, PhD; National Center for Rehabilitative Auditory Research, VA Portland Health Care System, 3710 SW U.S. Veterans Hospital Rd, Portland, OR 97239; 503-220-8262, ext 56210; fax: 503-721-1402.

Email: gabrielle.saunders@va.gov

http://dx.doi.org/10.1682/JRRD.2014.11.0275 


\section{INTRODUCTION}

Over the last decade, vast numbers of personnel from Operation Iraqi Freedom (OIF), Operation Enduring Freedom (OEF), and Operation New Dawn (OND) military operations have sustained blast-related injuries. As a result, considerable attention has been paid to combatrelated blast exposure and resultant traumatic brain injury (TBI) by the Department of Defense, Department of Veterans Affairs (VA), and public health experts [1-5]. Many blast-injured personnel receive diagnoses of TBI [6-7] and experience postconcussive symptoms long after leaving military service [8]. These problems are exacerbated because many blast-related TBIs are characterized as "mild" [9], so the servicemember often returns to full status duty soon after the event that caused the injury [5] and thus potentially sustains further blastrelated injuries. For instance, Fischer documented that of 307,282 TBIs documented across four branches of the military since $2000,82.5$ percent were classified as mild [9]. In addition to those individuals with formal diagnoses of TBI, other current and former military servicemembers who have not received formal TBI diagnoses also report symptoms typical of persistent postconcussive syndrome, such as headache, dizziness, poor memory, and difficulty concentrating [10-11].

In addition to typical postconcussive symptoms, many blast-exposed Veterans report difficulty understanding speech in noise and problems with auditory memory yet have no measureable peripheral auditory deficits [12-14]. Some authors have concluded that these auditory complaints reflect symptoms primarily associated with posttraumatic stress disorder (PTSD) [15], while others suggest they are associated with blastrelated TBI [16], and more specifically, blast-related damage to the central auditory system [11-12,17-18]. The proposed mechanism for such damage is that a primary blast injury leads to contusions from the brain moving within skull, hemorrhaging from the tearing of surface veins, and diffuse axonal injury as neurons are sheared and stretched in the lower- and mid-brainstem nuclei, thalamus, and corpus callosum and synaptic structures connecting nuclei within the central auditory system [6,19-20], which in turn negatively affects auditory and speech processing [18].

To date, one published study assesses the effects of blast on the central auditory system in Veterans by using behavioral measures of auditory function [18]. In that study, the performance of 36 hospitalized OIF/OEF servicemembers whose medical records documented one or more high-explosive blast events within the preceding year was compared with the performance of a control group consisting of 29 servicemembers without blast exposure. The groups were statistically matched on age, sex, and audiometric configuration. While all participants had pure tone thresholds of $\leq 25 \mathrm{~dB}$ hearing level (HL) at frequencies from 250 to $8,000 \mathrm{~Hz}$ and over 90 percent in each group had age-appropriate word recognition scores, 39 percent of the blast-exposed participants performed below normal on a measure of speech-in-noise (QuickSIN) [21] compared with 3 percent of the control group. Similarly, relative to the control group, a greater proportion of the blast-exposed group had abnormal performance in one or both ears on a measure of auditory temporal resolution (Gaps-In-Noise Test) [22] (39\% vs $3 \%$ ), on a test of binaural processing (masking level difference) [23-24] (33\% vs 3\%), and on a measure of speech segregation and competing speech (Staggered Spondaic Word Test [SSW]) (44\% vs 3\%). Performance deficits among the blast-exposed group were not universal, in that there were no between-group differences in the percentage of individuals with abnormal performance on measures of dichotic listening (Dichotic Digits Test) [25] and temporal pattern perception (Frequency Patterns Test) [26]. Gallun et al. concluded that even without obvious significant damage to the brain, evidence exists that a large proportion of blast-exposed individuals may have central auditory processing disorders [18].

In 2010, an informal survey of VA audiologists found that 92 percent encountered at least one OIF/OEF/OND Veteran per month who had difficulties hearing and yet had normal or almost normal pure tone sensitivity, with 53 percent of audiologists encountering between one and three per month and 39 percent encountering four or more per month [14]. In terms of clinical management for these individuals, no approaches have an evidence base. This is reflected in clinical practice in that although 33 percent of audiologists who responded to the survey reported providing Veterans with a personal frequency modulation system and 26 percent reported providing auditory training, 30 percent said they were unsure about what to do when they encountered these individuals. This illustrated the need to examine potentially effective interventions for this population. As part of a randomized controlled trial (RCT) to address this need, we collected baseline data from 99 normal-hearing, blast-exposed Veterans reporting 
auditory difficulties. These baseline data are reported here. The data provide further insight about the population and the relationship between reported auditory difficulties and auditory function. This sheds further light on the effects that blasts may have on the central auditory system and provides clinicians with further knowledge so they can make better-informed decisions about auditory rehabilitative clinical management.

\section{METHODS}

\section{Participants}

Participants were 99 Veterans recruited from the Portland VA Health Care System, Portland, Oregon, and the James A. Haley Veterans' Hospital, Tampa, Florida. Participants were recruited via fliers posted around the VA medical centers, and letters inviting participation were sent to Veterans who had recently attended an appointment at the Audiology and Speech Pathology, $\mathrm{OIF} / \mathrm{OEF} / \mathrm{OND}$, and/or TBI clinics. The number of participants recruited was based on a power analysis for the RCT. Figure 1 shows inclusion and exclusion criteria, while Table 1 provides demographic and audiometric data for participants at each test site separately. Table 1 shows that the mean four-frequency pure tone average
(4F-PTA) (mean of thresholds at 500, 1,000, 2,000, and $4,000 \mathrm{~Hz}$ ) was well within normal limits. Word recognition in quiet, assessed using the Maryland CNC 25-word list presented at $40 \mathrm{~dB}$ sensation level (SL), showed that the vast majority of participants had excellent word recognition scores, with 94.5 percent of participants scoring $\geq 90$ percent. Four individuals had relatively poor scores that were below 85 percent in both ears $(70 \%$ and $76 \%$, $78 \%$ and $82 \%, 80 \%$ and $80 \%$, and $84 \%$ and $84 \%$ for left and right ears, respectively). As is typical of a Veteran population, most participants were male. There were just two significant between-site differences: participants at the Tampa site had slightly poorer 4F-PTAs (by 2-3 dB) and were more racially diverse than those at the Portland site. It was considered unlikely that these minor differences affected performance on other test measures; thus, the remaining data are presented for both sites combined.

As required for study inclusion, all individuals reported exposure to one or more blasts or explosions from an improvised explosive device, a rocket-propelled grenade, land mine, grenade, etc. In addition, 35 percent had been involved in a vehicular accident that resulted in some form of head injury, 30 percent sustained a head injury following a fall, 26 percent sustained a head injury in some other manner, and 9 percent sustained a fragment wound or bullet wound above the shoulders. Further,

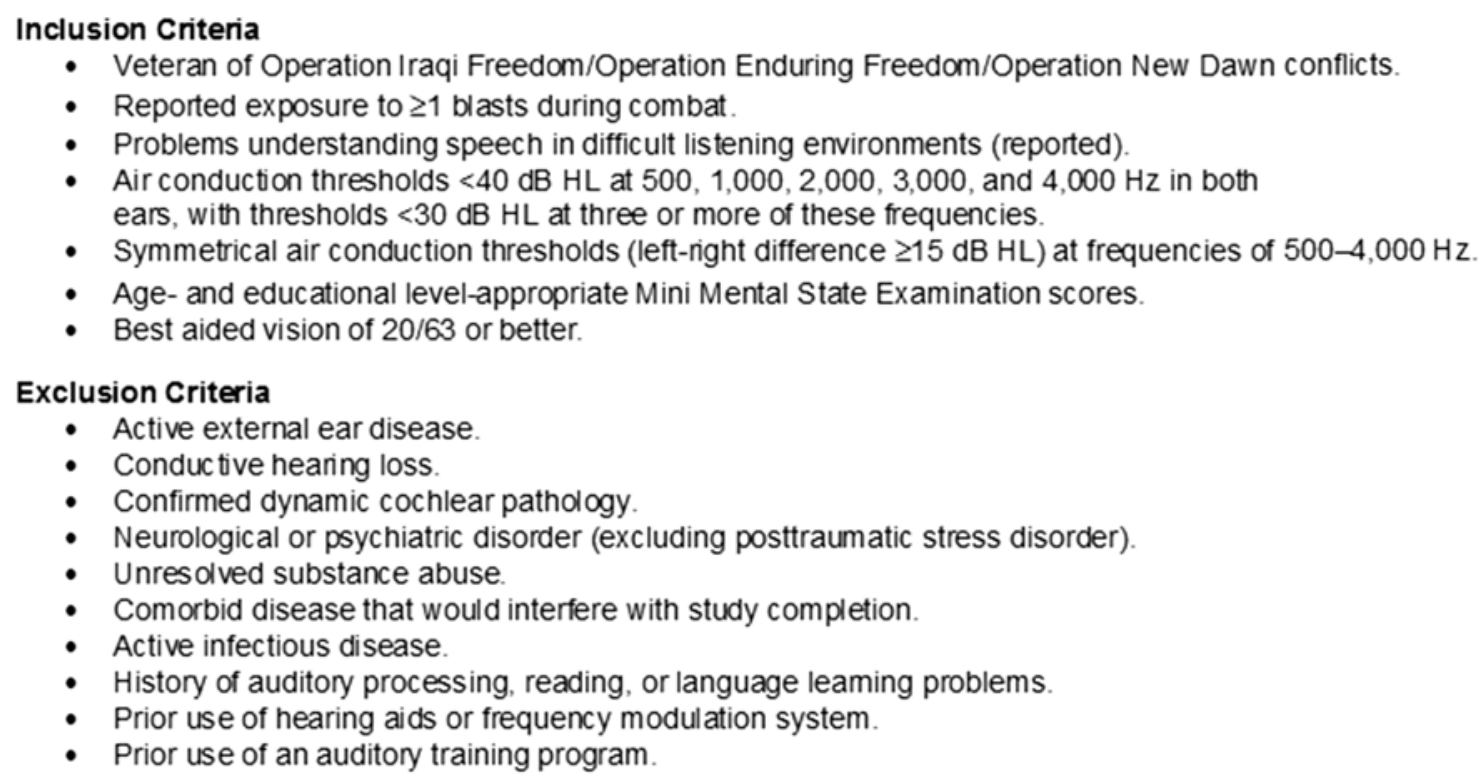

Figure 1.

Participant inclusion and exclusion criteria. $\mathrm{HL}=$ hearing level. 
JRRD, Volume 52, Number 3, 2015

Table 1.

Participant characteristics.

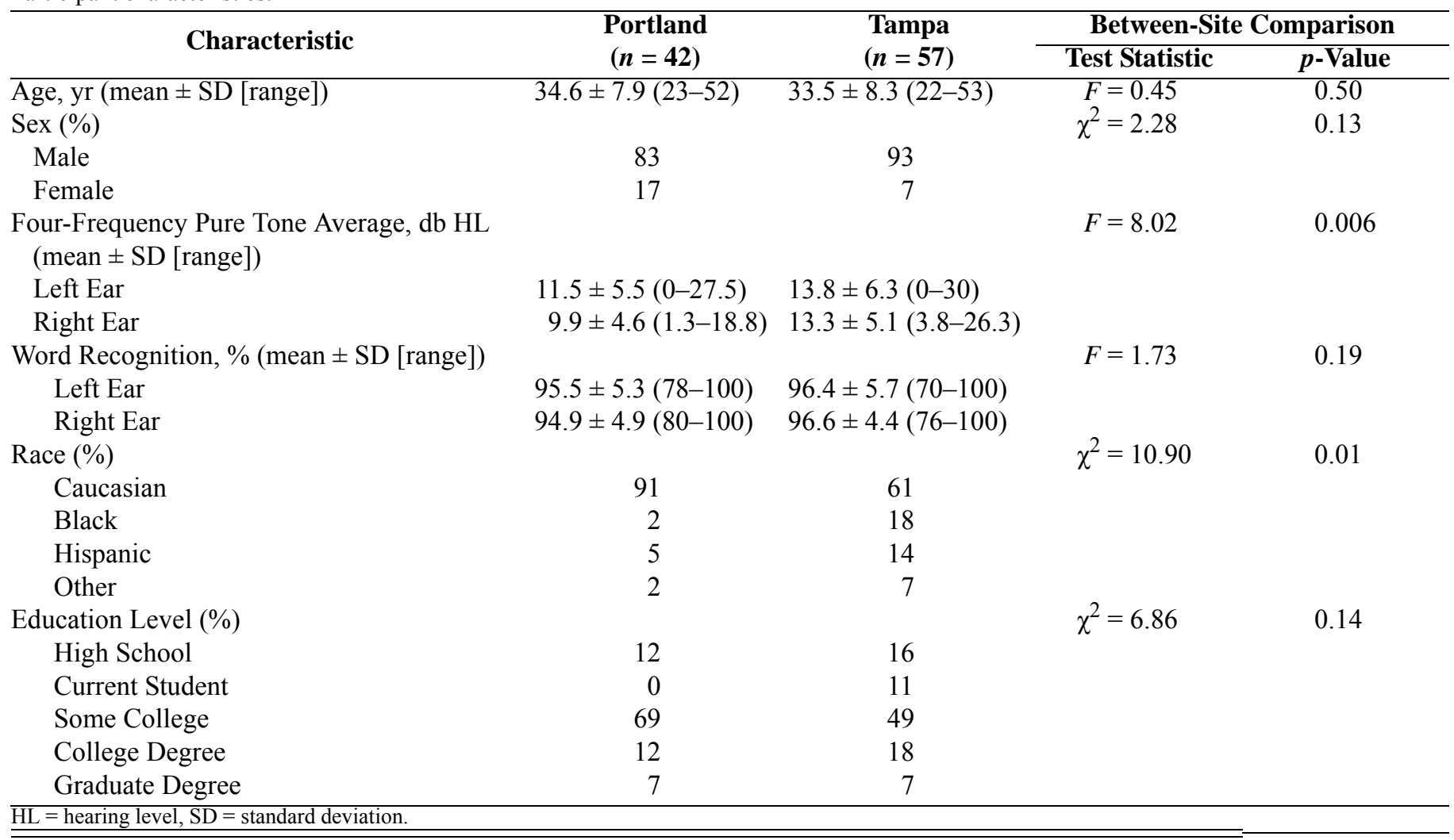

80 percent reported experiencing headache, 73 percent reported feeling dazed, 42 percent reported amnesia for the blast event, and 35 percent reported loss of consciousness immediately after the blast event. Despite these many reports of head-related injury, just 19 percent of participants had a confirmed diagnosis of TBI noted in their medical records.

\section{Test Measures}

Table 2 lists self-report and behavioral measures used in the RCT to characterize the study population and serve as outcome measures, further described next.

\section{Self-Report Measures}

Reported functional hearing problems were assessed with the Functional Hearing Questionnaire (FHQ). Myers developed the FHQ for audiology clinic use to quantify the degree and areas of perceived hearing difficulty among Veterans with a mild TBI complaining of listening problems with normal or near-normal audiograms. The questions were derived from common complaints that audiologists, speech-language pathologists, and a TBI neuropsychologist frequently encountered while working with patients with a TBI at the James A. Haley Veterans' Hospital. The questionnaire consists of nine questions that assess perceived hearing difficulties in nine communication situations (see Table 3 for each item). Participants rate their degree of difficulty in each situation on a 4-point scale: "not at all true" (1 point), "slightly true" (2 points), "mostly true" (3 points), or "very true" (4 points). A total score is obtained by summing points on each item. Possible scores range from 9 points (no functional hearing problems) to 36 points (maximum functional hearing problems).

Reported hearing disability in the domains of speech understanding, spatial hearing (direction, distance, and movement), and quality (ease of listening, naturalness,

\footnotetext{
*Myers, Paula (James A. Haley Veterans' Hospital, Tampa, FL). Email to: Gabrielle H. Saunders (National Center for Rehabilitative Auditory Research, VA Portland Health Care System, Portland, OR; and Department of Otolaryngology, Oregon Health and Science University, Portland, OR). 2010 Oct 5.
} 
Table 2.

Description of test measures.

\begin{tabular}{ll}
\hline \multicolumn{1}{c}{ Test Measure } & \multicolumn{1}{c}{ Brief Description } \\
$\begin{array}{l}\text { Functional Hearing Questionnaire } \\
\text { Speech, Spatial, and Qualities Questionnaire }\end{array}$ & $\begin{array}{c}\text { Measure of perceived communicative difficulties in common listening situations. } \\
\text { (direction, distance, movement), and quality (ease of listening, naturalness, clarity). }\end{array}$ \\
Hearing in Noise Test & Adaptive test of sentence understanding in presence of speech-shaped noise masker. \\
North American Listening in Spatialized & Adaptive test of auditory segregation skills measured for sentence understanding in pres- \\
Noise-Sentence Test & ence of same or different competing talker and with and without spatial separation. \\
Adaptive Tests of Temporal Resolution & Gap detection measure of temporal resolution that assesses within-channel and across- \\
& channel gap detection. \\
Modified DS & Measure of auditory working memory assessing DS-Forward and DS-Backward. \\
Time Compressed Speech Test & Sentence-based measure of ability to understand speeded speech. \\
Staggered Spondaic Word Test & Measure of ability to segregate competing speech signals using spondaic word pairs. \\
Woodcock Johnson Story Recall subtest of & Measure of ability to recall content of stories that range in length and content \\
$\quad$ Woodcock Johnson Tests of Achievement-III & complexity. \\
Stroop Color and Word Test & Measure of ability to ignore irrelevant stimuli. \\
\hline DS = Digit Span Test. & \\
\hline
\end{tabular}

Table 3.

Functional Hearing Questionnaire (FHQ) scores.

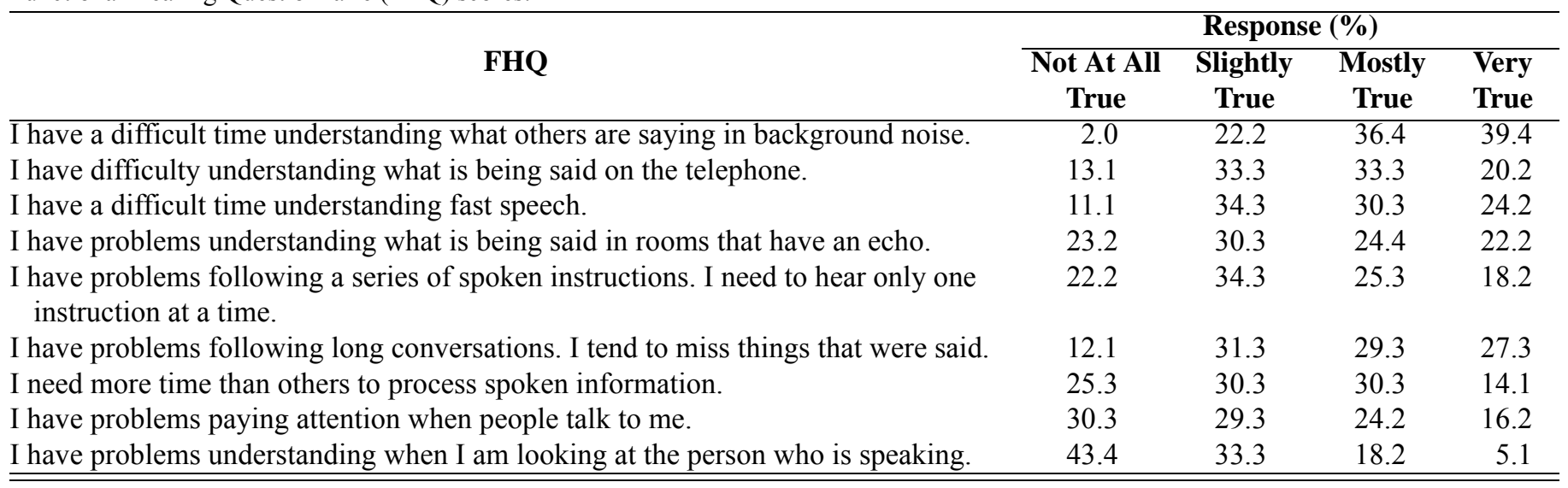

and clarity) was measured using the Speech, Spatial, and Qualities (SSQ) questionnaire [27]. The SSQ questionnaire consists of 50 statements to which participants respond on a 10-point scale from "not at all" ( 0 points) to "perfectly" (10 points). Average scores on each domain are computed. Possible scores range from 0 points (maximum disability) to 10 points (no disability).

\section{Behavioral Measures}

Speech understanding in noise was assessed using the Hearing in Noise Test (HINT), in which the signal to noise ratio (SNR) for 50 percent correct identification of sentences is obtained using an adaptive procedure, yielding a speech reception threshold in noise (SRTN) [28]. The test materials consist of 10 equivalent 20 -sentence lists and accompanying masking noise shaped to the average longterm spectrum of the sentences. The participant's task is to repeat back each sentence. Sound field testing was conducted in a sound-attenuating booth for two conditions: (1) two loudspeakers at a distance of $1 \mathrm{~m}$ from the listener's head with speech presented from $0^{\circ}$ azimuth and noise from $90^{\circ}$ azimuth and (2) two loudspeakers at a distance of $1 \mathrm{~m}$ from the listener's head with speech presented from $0^{\circ}$ azimuth and noise from $270^{\circ}$ azimuth. The level of the noise masker was fixed at $65 \mathrm{~dB}$ sound pressure level (SPL); the level of the sentences was adjusted adaptively depending on performance. Specifically, for each sentence repeated correctly, the level of the sentences was decreased (SNR made more adverse) in $4 \mathrm{~dB}$ steps for sentences 1 through 4 , and in $2 \mathrm{~dB}$ steps thereafter. If one 
or more words was repeated incorrectly, the sentence level was increased (SNR made less adverse) instead. The SRTN was computed by averaging the SNR for sentences 5 through 20, along with the SNR at which a 21 st sentence would have been presented. Any occasion for which the standard deviation (SD) of presentation levels met or exceeded the 95th percentile for the distribution of SDs as defined in the HINT manual was rerun. Results from the two conditions were averaged because all participants had symmetrical hearing.

Auditory segregation skills were measured using the North American Listening in Spatialized Noise-Sentence Test (NA LiSN-S) [29]. Target sentences are spoken by a female in the presence of a competing signal that is either the same female voice or a male voice narrating a story. The participant's task is to repeat back each target sentence. Testing was conducted binaurally through headphones. The presentation level of the competing signal was fixed at $55 \mathrm{~dB}$ SPL, and the level of the sentences was varied adaptively from a starting level of $62 \mathrm{~dB}$ SPL as follows: The sentence level was decreased by $2 \mathrm{~dB}$ (SNR made more adverse) if the listener repeated back more than 50 percent of the words correctly and increased by $2 \mathrm{~dB}$ (SNR made less adverse) if the listener repeated back less than 50 percent of the words correctly. The level remained unchanged if exactly 50 percent of the words were repeated correctly. Four conditions were tested: (1) target sentence with competing speech presented by the same talker at $0^{\circ}$ azimuth, (2) target sentence with competing speech presented by different talkers at $0^{\circ}$ azimuth, (3) target sentence presented from $0^{\circ}$ azimuth and competing speech at $\pm 90^{\circ}$ by the same talker, and (4) target sentence presented from $0^{\circ}$ azimuth and competing speech at $\pm 90^{\circ}$ by different talker. For analyses, two variables were computed: spatial advantage (the extent to which the listener gains advantage for spatial separation) $=$ the difference in SNR between conditions 1 and 3, and talker advantage (the extent to which the listener gains advantage for differing-talker cues) = the difference in SNR between conditions 1 and 2 .

Temporal resolution was assessed using the Adaptive Tests of Temporal Resolution (ATTR) [30], in which gap detection thresholds are measured using an adaptive twointerval forced choice paradigm. The listener is presented with two bursts of noise, each $150 \mathrm{~ms}$ in duration and one of which has a silent gap embedded in it. The listener's task is to identify the interval in which the burst of noise has the silent gap embedded in it. The duration of noise prior to the gap is always a fixed duration (400 ms) and the duration of the noise after the gap varies randomly in duration between 250 and $350 \mathrm{~ms}$ [31]. If the target interval is identified correctly on two consecutive occasions, the duration of the gap is decreased by a factor of 1.2 (task is made more difficult). If the interval is identified incorrectly, the duration of the gap is increased by a factor of 1.2 (task is made easier). This targets the paradigm to reach the 70.7 percent correct gap detection threshold. Within-channel (WC) and across-channel (AC) gap detection thresholds were measured. For the WC task, both the first (before the gap) and second (after the gap) markers were narrow bands of noise centered at 2,000 Hz. For the AC task, the first marker was a narrow band of noise centered at $2,000 \mathrm{~Hz}$, while the second marker was a narrow band of noise centered at $1,000 \mathrm{~Hz}$. According to some [32-33], WC gap detection is easier than AC gap detection because WC gap detection only requires monitoring in one neural channel while AC gap detection requires monitoring in different channels for onset and offset. Testing was conducted binaurally through HD 201 headphones (Sennheiser; Wedemark, Germany) at a comfortable listening level. Actual output levels for each participant were not measured because data show that presentation level has a negligible effect of gap detection thresholds once the signal is above 25 to $30 \mathrm{~dB}$ SL [31]. Two repetitions in each condition were measured. If the geometric means of the two repetitions differed by more than a factor of 2, a third run was completed, and the two closest thresholds were averaged for the final gap detection threshold.

The ability to understand speeded speech was assessed using the Time Compressed Speech Test (TCST) [34]. The TCST consists of Institute of Electrical and Electronics Engineers sentences [35] that have been time-compressed at 50 and 60 percent using custom software [34]. Participants are presented with 10 sentences at each compression rate through a loudspeaker located at $0^{\circ}$ azimuth $1 \mathrm{~m}$ from the listener's location at a presentation level of $55 \mathrm{~dB}$ HL. Each set of sentences was preceded by 10 practice sentences presented at a normal speed. Sentences were scored in terms of the number of key words repeated correctly (5 key words per sentence) and a percent correct score computed for each condition.

Ability to segregate competing speech signals was measured with the SSW [36]. The SSW consists of 40 spondee word pairs (e.g., day-light, back-door) presented through TDH-39 headphones at a level of $55 \mathrm{~dB}$ HL. On 
each trial, one spondee is presented to the left ear and one is presented to the right ear in a time-staggered manner such that the first syllable of the first spondee is presented in isolation, the second syllable of the first spondee is then presented at the same time as the first syllable of the second spondee, and finally, the second syllable of the second spondee is presented in isolation. The listener's task is to repeat back each spondee. The test began with the first spondee presented to the right ear and the second spondee presented to the left ear. The order of ear presentation was alternated in subsequent trials. The total number of errors was used as the primary metric of interest because it has been noted as the most appropriate metric when data are from individuals with normal hearing [36]. However, analyses examining left competing (LC), left noncompeting (LNC), right competing (RC), and right noncompeting (RNC) errors were also conducted.

Auditory working memory was assessed using a modified recorded version of the Digit Span Test (DS), a subtest of the Wechsler Adult Intelligence Scale-3rd edition (WAIS-III) [37]. This test involves both auditory and cognitive processing. DS-Forward (memory for digits repeated in the sequence they were presented) and DSBackward (memory for digits repeated in the reverse sequence they were presented) scores are obtained. The number of digits in a sequence can range from two to nine in DS-Forward and from two to eight in DS-Backward. Each sequence length has two trials (two trials of a 2digit sequence, two trials of a 3-digit sequence, etc.). If all digits are repeated in the appropriate order, 1 point is awarded; if the response is in any way incorrect, 0 points are awarded. If either of the two trials in a given sequence length is repeated correctly, the next sequence length is presented. If neither trial in a sequence length is repeated correctly, testing is terminated. DS scaled scores were obtained using the age-appropriate conversion table in the WAIS-III administration and scoring manual. Scaled scores have a mean of 10 and SD of 3. For the current study, the DS stimuli were modified by making a recording (in lieu of live voice presentation) of a female speaking the digit sequences and replacing the digit 7 (bisyllabic) with the digit 10 (monosyllabic).

Working memory for spoken language was assessed with the Woodcock Johnson Story Recall subtest of the Woodcock Johnson Tests of Achievement-III (WJ-III) [38]. Listeners must recall the content of stories that range in length and content complexity from two sentences with 3 content units to five sentences with 21 content units. This measure requires both auditory and cognitive processing. Recordings of the stories were presented at a comfortable listening level through a loudspeaker located at $0^{\circ}$ azimuth $1 \mathrm{~m}$ from the listener. Participant responses were recorded for later transcription and scoring. Due to the subjective nature of the process, the transcriptions were independently scored by two members of the research team. One point was awarded for each content unit correctly recalled. Scores from the two scorers were averaged and a total score was computed. This value was converted into a standard score using the WJ-III scoring software. Standard scores have a mean of 100 and SD of 15.

Attention and cognitive interference was measured using the Stroop Color and Word Test [39]. While this measure does not involve auditory processing, it was included because it assesses cognitive flexibility and resistance to interference from outside stimuli, which would be likely to influence an individual's ability to cope with cognitive stress and process complex input such as speech in difficult listening situations. Participants are shown 100 test items in each of three conditions: a Word page, a Color page, and a Color-Word page. The Word page consists of the words "red," "blue," and "green" printed in black ink. The Color page consists of the item "XXXX" printed in red, blue, or green ink. The Color-Word page consists of the words from the Word page printed in the colors from the Color page. For the Word page, participants read the words as quickly as they can, while for the Color and Color-Word pages, participants name the color of the ink as quickly as they are able. A Stroop Interference t-score is the difference between the color-word and predicted interference scores. This was obtained using scoring software provided by Golden and Freshwater [39]. T-scores have a mean of 50 and SD of 10.

\section{Procedures}

The methods for the initial two study visits in the $\mathrm{RCT}$ are described next. It is the data from these two visits that were used to characterize the study population and examine relationships between reported auditory difficulties and auditory function. Participants received \$25 for each study visit.

\section{Visit 1}

Participants signed a consent form to confirm that they understood the study purpose and procedures. Inclusion-exclusion assessments were then completed. Audiometry was conducted in a sound-attenuating booth using 
clinically recommended procedures [40]. All other tests were conducted in a quiet, well-lit room. The case history and FHQ were completed in interview format. The visit lasted between 1 and $1.5 \mathrm{~h}$.

\section{Visit 2}

Visit 2 took place within 3 wk of visit 1. Performance on the behavioral outcome measures was assessed (HINT, ATTR, TCST, SSW, DS, Woodcock Johnson Story Recall, and Stroop Color and Word Test). With the exception of the Stroop Color and Word Test, all testing was conducted in a sound attenuating booth. The HINT, DS, TCST, and Woodcock Johnson Story Recall were conducted in the sound field; the ATTR and SSW were administered via headphones. The Stroop Color and Word Test was conducted in a quiet, well-lit room. The visit lasted between 1.5 and $2 \mathrm{~h}$.

\section{RESULTS}

\section{Analyses}

Study data were collected and managed using REDCap electronic data capture tools hosted at Oregon Health and Science University [41]. REDCap (Research Electronic Data Capture) is a secure Web-based application designed to support data capture for research studies, providing (1) an intuitive interface for validated data entry, (2) audit trails for tracking data manipulation and export procedures, (3) automated export procedures for seamless data downloads to common statistical packages, and (4) procedures for importing data from external sources. De-identified data were entered by hand into REDCap by two members of the research team at each test site. One individual read aloud the values while the other entered them into the database. The values were then read back from the database to double-check entry. The final data were downloaded into SPSS version 21 (IBM Corporation; Armonk, New York) for analysis. Distributions of values for each variable were examined to further check data entry. Any outlier values were checked against the source data and corrected if necessary.

\section{Reported Hearing Difficulties}

The FHQ and SSQ questionnaire were used to characterize reported hearing-related difficulties. Table 3 shows the percentage of individuals giving responses of "not at all true," "slightly true," "mostly true," and "very true" for each FHQ item. Understanding speech in noise was the most common problem for participants, with over 75 percent responding mostly or very true to the statement "I have a difficult time understanding what others are saying in background noise." Other listening situations to which more than half the participants responded mostly or very true were difficulty following long conversations (56.6\%), difficulty understanding fast speech (54.3\%), and difficulty on the telephone (53.5\%). The least problematic situations for participants were difficulty understanding when looking at the person who is speaking (23.3\% responded this was mostly or very true) and problems paying attention to speech ( $40.4 \%$ responded this was mostly or very true). Relative to the unpublished data of Myers (Figure 2, dark bars) collected between Fall 2008 and Spring 2009, the data from participants in this study (Figure 2, light bar) are more similar to Myers' groups of normalhearing, blast-exposed Veterans (mean age: $35.4 \mathrm{yr}$, range:

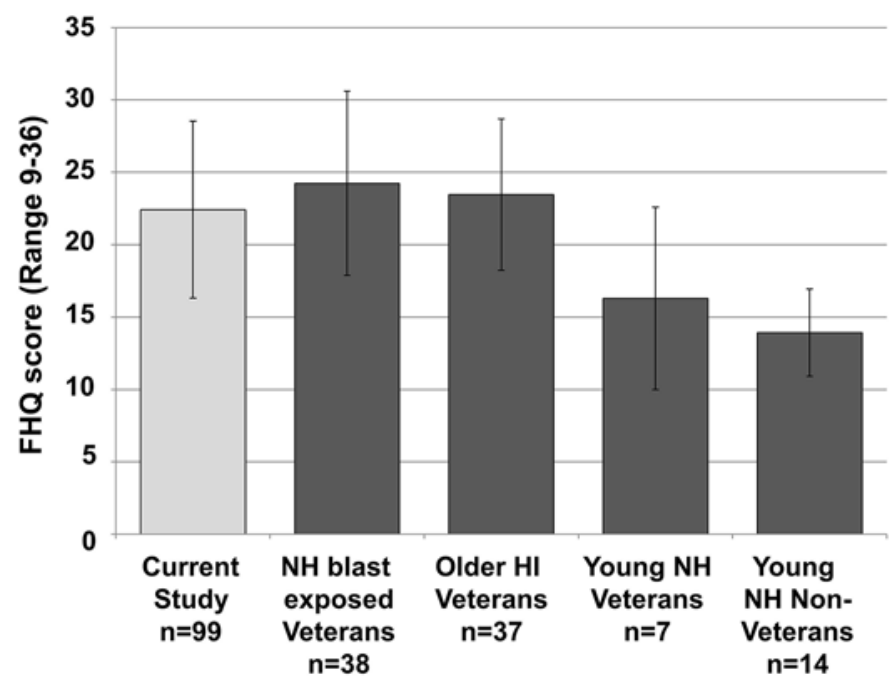

Figure 2.

Mean Functional Hearing Questionnaire (FHQ) scores and error bars showing \pm 1 standard error for individuals in current study (light gray bar) and data collected by Myers ${ }^{\star}$ from blast-exposed, normal-hearing $(\mathrm{NH})$ Veterans; older hearing-impaired (HI) Veterans; young $\mathrm{NH}$ Veterans with no blast exposure; and young $\mathrm{NH}$ non-Veterans, respectively (dark gray bars). "Myers, Paula (James A. Haley Veterans' Hospital, Tampa, FL). Email to: Gabrielle H. Saunders (National Center for Rehabilitative Auditory Research, Department of Veterans Affairs Portland Health Care System, Portland, OR; and Department of Otolaryngology, Oregon Health and Science University, Portland, OR). 2010 Oct 5. 
18-57 yr) and older hearing-impaired Veterans (mean age: $74.1 \mathrm{yr}$, range: 70.6-77.6 yr) than they are to her groups of young normal-hearing individuals (mean age: $26.9 \mathrm{yr}$, range: $20-34 \mathrm{yr}$ ).

Table 4 shows the mean \pm 1 SD obtained on the SSQ questionnaire for participants in the current study along with SSQ questionnaire data from other studies. A higher SSQ questionnaire score indicates fewer hearing difficulties. Once again, these data illustrate that the SSQ question- naire scores of participants in this study are more similar to the scores of older individuals with hearing loss in Gatehouse and Noble [27] than they are to either the young or older normal-hearing individuals in Bahn et al. [42].

\section{Behavioral Measures}

Table 5 shows the mean \pm 1 SD of performance on each behavioral test. Also shown are values on each measure obtained from other sources. Where possible, these

Table 4.

Speech, Spatial, and Qualities (SSQ) questionnaire scores (mean \pm standard deviation). Higher SSQ score indicates fewer hearing difficulties.

\begin{tabular}{lcccc}
\hline \multicolumn{1}{c}{$\begin{array}{c}\text { SSQ } \\
\text { Questionnaire }\end{array}$} & $\begin{array}{c}\text { Current Study } \\
(\boldsymbol{n}=\mathbf{9 9})\end{array}$ & $\begin{array}{c}\text { Bahn et al., 2012 [42] } \\
(\boldsymbol{n}=\mathbf{4 8})\end{array}$ & $\begin{array}{c}\text { Bahn et al., 2012 [42] } \\
(\boldsymbol{n}=\mathbf{4 8})^{\dagger}\end{array}$ & $\begin{array}{c}\text { Gatehouse and Noble, 2004 [27] } \\
(\boldsymbol{n}=\mathbf{1 5 3})^{\ddagger}\end{array}$ \\
\hline Speech & $5.3 \pm 1.7$ & $8.5 \pm 0.7$ & $7.3 \pm 1.5$ & $4.4 \pm 2.4$ \\
Spatial & $6.8 \pm 1.9$ & $8.6 \pm 0.7$ & $7.5 \pm 1.6$ & $5.2 \pm 2.6$ \\
Qualities & $6.3 \pm 1.4$ & $9.4 \pm 0.6$ & $8.3 \pm 1.1$ & $6.5 \pm 2.7$ \\
Overall & $6.1 \pm 1.5$ & $8.8 \pm 0.6$ & $7.7 \pm 1.2$ & $5.4 \pm 2.6$
\end{tabular}

*Younger participants with normal hearing (age: $18.6 \pm 1.0 \mathrm{yr}$ ) with thresholds from 0.25 to $3.0 \mathrm{kHz} \leq 25 \mathrm{~dB} \mathrm{HL}$.

${ }^{\dagger}$ Older participants with normal hearing (age: $70.9 \pm 4.1 \mathrm{yr}$ ) with thresholds from 0.25 to $3.0 \mathrm{kHz} \leq 25 \mathrm{~dB} \mathrm{HL}$.

${ }^{\ddagger}$ Older participants with hearing loss (age: $71.0 \pm 8.1 \mathrm{yr}$ ): better ear 4F-PTA $=38.3 \pm 15.5 \mathrm{~dB}$ HL and worse ear 4F-PTA $=52.7 \pm 24.4 \mathrm{~dB} \mathrm{HL}$.

$4 \mathrm{~F}-\mathrm{PTA}=$ four-frequency pure tone average, $\mathrm{HL}=$ hearing level.

Table 5.

Mean \pm standard deviation (SD) and range of performance scores on behavioral measures along with normative data and percentage of individuals with performance $\geq 1$ SD below mean.

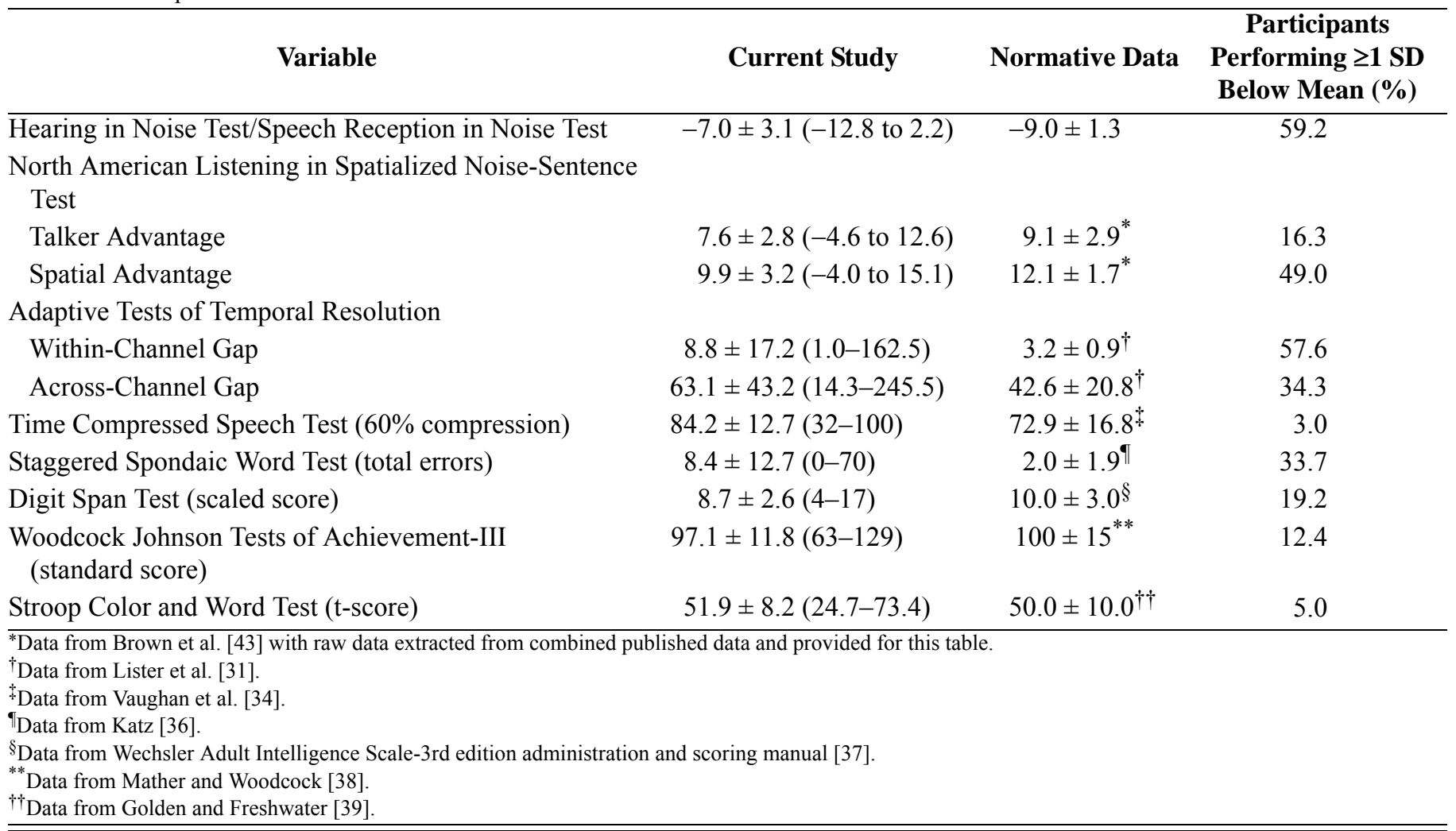


sources are for an age-equivalent normal-hearing population or from age-equivalent published normative data. Finally, for each behavioral measure, the percentage of individuals in the present study who performed $\geq 1$ SD below the mean of the values is shown. Note that, based on the properties of a normal distribution, 15.9 percent of individuals would be expected to perform $\geq 1$ SD below the mean on any particular measure. The data from each test measure are discussed separately next.

\section{Hearing in Noise Test}

As recommended in the HINT manual [44], sound field norms using the same setup and test procedure were collected and used in comparison with the current data set. The mean speech SRTN of $-7.0 \mathrm{~dB}$ obtained here is poorer than the mean SRTN of $-9.0 \mathrm{~dB}$ obtained from 26 young normal-hearing listeners in the sound field. Applying the published HINT SD of $1.3 \mathrm{~dB}$, we saw that almost 60 percent of participants here performed $\geq 1$ SD poorer than normal hearing listeners, indicating a measureable performance deficit for understanding of speech in noise in the majority of individuals in this sample.

\section{North American Listening in Spatialized Noise-Sentence Test}

Mean NA LiSN-S talker and spatial advantages observed here were poorer than for the 53 younger normal-hearing listeners (age range: 19-30 yr) reported elsewhere [43]. Specifically, compared with Brown et al., performance for 49 and 16 percent of the participants was $\geq 1$ SD below the mean for spatial and talker advantage, respectively [43]. Spatial advantage requires use of binaural processing while talker advantage requires use of cues such as pitch to distinguish the signal and masker [45]. The data thus indicate that as a group, the blast-exposed Veterans in this study have a deficit in binaural processing abilities but do not have a deficit in their use of pitch cues.

\section{Adaptive Tests of Temporal Resolution}

The group mean $\mathrm{WC}$ and $\mathrm{AC}$ gaps of participants in this study were considerably greater (poorer performance) than those of 30 normal-hearing males (mean age: $25.2 \mathrm{yr}$, range: $20-37 \mathrm{yr}$ ) reported by Lister et al. [46]. Indeed, relative to the participants of Lister et al., 57.6 and 34.3 percent of participants demonstrated poorer performance by $\geq 1 \mathrm{SD}$ on the $\mathrm{WC}$ and $\mathrm{AC}$ gap conditions, respectively. Research suggests that gap detection is associated with central rather than peripheral processing [47-49]. This is consistent with the presence of central temporal processing deficits among the group.

\section{Time Compressed Speech Test}

Mean performance on the TCST for 50 percent timecompressed sentences was near ceiling $(90.9 \% \pm 11.0 \%)$; therefore, only data for 60 percent time-compressed sentences were examined further. On average, participants obtained a higher score than those of Vaughan et al. [34], with just 3 percent performing $\geq 1$ SD below the mean. Older age may be a contributing factor to this finding, because the participants of Vaughan et al. ranged from 50 to $75 \mathrm{yr}$ old. Although audibility was controlled for in Vaughan et al., many of their participants had mild to moderate sensorineural hearing loss, which could have affected speech clarity. The lack of available published data is unfortunate and makes it difficult to draw further conclusions from this test measure. It is worth noting, however, that scores of participants in this study were highly variable, ranging from 32 to 100 percent.

\section{Staggered Spondaic Word Test}

The mean total number of errors on the SSW was considerably higher than the age-appropriate average (8.4 vs 2.0) [36]. However, it has been suggested by Katz that a value of 6 should be used as a cut-off for normal performance for individuals aged 12 to $59 \mathrm{yr}$ [36]. When applying this definition, 33.7 percent of study participants had abnormally poor SSW performance. Further, the range of scores was considerable, from 0 to 70 errors. Examination of the LC, LNC, RC, and RNC errors shows no particular pattern of deficit. Specifically, 7.1 and 9.1 percent of the study population had performances outside of normal limits for RNC and RC conditions, respectively, while the numbers for LNC and LC were 10.1 and 9.1 percent, respectively. Closer examination of the data showed that of the 14 participants who performed outside normal limits on one or more conditions, 4 had abnormal performance on all four conditions, 1 on three conditions (RNC, $\mathrm{RC}$, and LNC), 7 on varying combinations of two conditions, and 2 on one condition (LC). Among the seven with abnormal performance on two conditions, all but one combination (RNC and LC) of abnormal performance was represented. Given this, we concluded that no pattern of errors exists and that the SSW results indicate that the study population is showing a generalized deficit in speech segregation and competing speech ability. 


\section{Digit Span Test}

Mean DS scaled scores were below that of normative data, with 19 percent of participants having a score $\geq 1$ SD below the mean. It is important to also examine DSForward and DS-Backward scores individually because they are thought to measure different skills-with DSForward primarily assessing short-term auditory memory and DS-Backward assessing the ability to manipulate verbal information while in temporary storage, a higher-level task [50]. Table 6 shows DS-Forward and DS-Backward scores along with those scores obtained from a group of 1,250 individuals (age range: $16-89 \mathrm{yr}$ ) and from a group of 22 individuals with TBI [51]. We saw that the performance of individuals in this study is similar to that of the normative sample of Wilde et al. Wilde et al. went on to determine that only 5 percent of their normative population had a difference in score between DS-Forward and DS-Backward that was $\geq 6$, but that 23 percent of individuals with TBI had a DS-Forward and DS-Backward difference score of $\geq 6$. The proportion of individuals in this study with a DS-Forward and DS-Backward difference score of $\geq 6$ was just 7.1 percent, very similar to the normative group of Wilde et al. Together, these data indicate that as a group, the blast-exposed Veterans in the study do not have working memory deficits as assessed using the DS.

\section{Woodcock Johnson Story Recall}

Participants had average performance on the Woodcock Johnson Story Recall, with just 12 percent obtaining a standard score that was $\geq 1$ SD below the mean, suggesting that working memory for spoken language is not a particular problem for the study participants.

\section{Stroop Color and Word Test}

Performance on the Stroop Color and Word Test was average for age-appropriate norms, with only 5 percent of participants here obtaining a t-score $\geq 1$ SD below the mean, suggesting that inability to ignore irrelevant stimuli is not a particular problem among the study participants.

In summary, based on the properties of a normal distribution, 15.9 percent of individuals would be expected to perform $\geq 1$ SD below the mean. The behavioral measures on which considerably more than 15.9 percent of participants performed $\geq 1$ SD below the mean were the HINT, NA LiSN-S Spatial advantage, ATTR (AC and WC conditions), and SSW.

\section{Performance Across Test Measures}

Figure 3 shows a histogram of the total number of behavioral measures on which each individual performed $\geq 1$ SD below the mean (range: $0-10$ ). The majority of participants $(52.5 \%)$ performed $\geq 1$ SD below the mean on between three and five measures and 37.3 percent performed $\geq 1$ SD below the mean on fewer than three measures. Just 10 percent performed $\geq 1$ SD below the mean on more than five measures and 0 percent performed $\geq 1$ $\mathrm{SD}$ below the mean on all 10 measures.

\section{Relationships Between Reported Functional Difficulties and Measured Performance}

Pearson correlations were conducted to examine whether reported functional difficulties as measured by the FHQ were associated with particular performance deficits on the behavioral measures. To adjust for multiple testing, only correlations with a $p$-value of $<0.005$ were considered significant. Performance on the HINT, NA LiSN-S, ATTR, and Stroop Color and Word Test were not associated with any FHQ item. Likewise, items from the FHQ regarding difficulty understanding speech in background noise and problems understanding in rooms with an echo were not associated with scores on any behavioral measure. However, there were a number of moderate, but statistically significant, correlations between FHQ items and performance (Table 7). In each instance, the association was such that more reported

Table 6.

Digit Span Test scores (mean \pm standard deviation).

\begin{tabular}{lccc}
\hline \multicolumn{1}{c}{ Digit Span Test } & $\begin{array}{c}\text { Current Study } \\
(\boldsymbol{n}=\mathbf{9 9 )}\end{array}$ & $\begin{array}{c}\text { Normative Sample } \\
(\boldsymbol{n}=\mathbf{1 , 2 5 0 )}\end{array}$ & $\begin{array}{c}\text { Individuals with TBI } \\
(\boldsymbol{n}=\mathbf{2 2})\end{array}$ \\
\hline Forward & & $9.92 \pm 2.32$ & $9.82 \pm 1.94$ \\
Backward & $8.79 \pm 2.09$ & $6.43 \pm 2.34$ & $5.68 \pm 1.81$ \\
Difference & $6.31 \pm 2.17$ & 3.49 & 4.14 \\
\hline TBI = traumatic brain injury. & 2.47 & & \\
\hline \hline
\end{tabular}




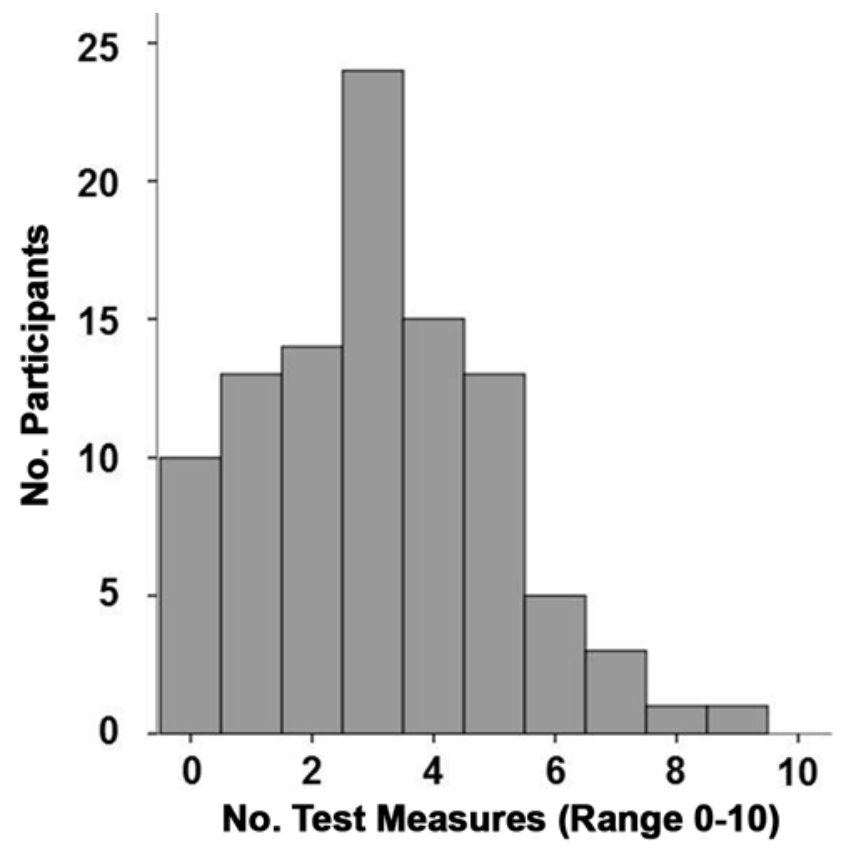

Figure 3.

Histogram showing number of test measures on which participants performed $\geq 1$ standard deviation below mean.

functional difficulties were associated with poorer performance on the behavioral test, and what is more, each association makes logical sense. For example, the DS scaled score, which is a measure of working memory, was significantly associated with problems following a series of spoken instructions and problems following long conversations - both of which require the ability to store and recall information. Likewise, the TCST 60 percent compression, a measure of speeded speech, was significantly correlated with difficulty understanding fast speech and needing more time than others to process spoken speech - problems that would arise if an individual's speed of processing was slower than normal. Finally, the WJ-III standard score, a measure of story recall, was associated with problems following a series of spoken instructions, which, like story recall, requires the ability to keep track of and recall spoken content.

In summary, results show that the sample of 99 normal-hearing, blast-exposed Veterans who reported problems hearing in difficult listening environments displayed performance deficits on a variety of behavioral measures and that these deficits were meaningfully associated with their reported problems.

\section{DISCUSSION AND CONCLUSIONS}

The objective of this article was to present data characterizing a group of blast-exposed OIF/OEF/OND Veterans, all of whom had clinically normal hearing sensitivity and yet reported hearing problems in difficult listening situations, and examine relationships between their reported difficulties and measured hearing performance. To this end, data collected from 99 blast-exposed Veterans with hearing difficulties but clinically normal hearing sensitivity were examined as part of a larger RCT in which auditory rehabilitative interventions were compared. As seen in Tables 3 and 4, participants perceived considerable hearing difficulty, such that their FHQ and SSQ questionnaire scores were more like those of older individuals with hearing impairment ${ }^{*}$ [27], than they were to individuals of equivalent age and normal hearing sensitivity $[9,42]$. A similar finding was reported in a population of OIF Veterans with blast-related TBI, among whom 11 percent reported hearing difficulties yet had clinically normal hearing [12] and in a survey of VA audiologists that found that 92 percent of audiologists encountered at least one OIF/OEF Veteran a month who had difficulties hearing and yet had normal or almost normal pure tone sensitivity, with 53 percent of audiologists encountering between one and three per month and 39 percent encountering four or more per month [14].

Participants in this study also showed measureable performance deficits on the HINT, NA LiSN-S Spatial advantage, ATTR, and SSW - measures of speech understanding in noise, binaural processing, temporal resolution, and speech segregation, respectively. As described in detail previously, Gallun et al. reported similar findings, albeit for the most part using a different set of test measures [18]. Specifically, they determined that among their sample of 36 blast-exposed Veterans, a third or more performed below normal on measures of speech in noise (QuickSIN), auditory temporal resolution (Gaps-InNoise Test), binaural processing (masking level difference), and speech segregation and competing speech (SSW). Also, similar to the findings of Gallun et al., the performance of the participants in the current study was

\footnotetext{
*Myers, Paula (James A. Haley Veterans' Hospital, Tampa, FL). Email to: Gabrielle H. Saunders (National Center for Rehabilitative Auditory Research, VA Portland Health Care System, Portland, OR; and Department of Otolaryngology, Oregon Health and Science University, Portland, OR). 2009 Nov 17.
} 
Table 7.

Significant Pearson correlations at $p<0.005$ after Bonferroni correction for multiple analyses between scores on Functional Hearing Questionnaire (FHQ) and performance measures.

\begin{tabular}{|c|c|c|}
\hline FHQ Item & Performance Variable & $r$-Value \\
\hline Difficulty understanding on telephone. & TCST (60\% compression) & -0.306 \\
\hline Difficulty understanding fast speech. & TCST (60\% compression) & -0.284 \\
\hline Problems following series of spoken instructions. & DS (scaled score) & -0.310 \\
\hline Problems following long conversations. & DS (scaled score) & -0.280 \\
\hline Need more time than others to process spoken information. & TCST (60\% compression) & -0.303 \\
\hline Problems understanding when looking at person who is speaking. & TCST (60\% compression) & -0.415 \\
\hline Problems understanding when looking at person who is speaking. & SSW (total errors) & 0.395 \\
\hline
\end{tabular}

not universally poor. The majority of individuals performed at normal levels on the DS (auditory working memory), TCST (rapid speech understanding), Stroop Color and Word Test (attention and cognitive interference), and Woodcock Johnson Story Recall (memory for narrative).

The finding that performance is poor on some but not all measures suggests that participants exhibit taskspecific deficits rather than a global functional deficit. It has, however, been noted in both civilian and Veteran populations that poor effort and symptom exaggeration are common following TBI [52-53] and that poor effort can account for more than 50 percent of the variance on cognitive performance [54]. Indeed, it has been suggested that Veterans who sustained TBI that report postconcussive symptoms differ from those who do not report postconcussive symptoms on, among other things, degree of possible symptom exaggeration, poor effort, depression, and traumatic stress, while postconcussive disorder rarely occurred in the absence of these symptoms [55]. While not assessed formally, our data showing that more than one-third of individuals performed within $1 \mathrm{SD}$ of the mean on $\geq 8$ of the 10 measures and that over 50 percent performed within $1 \mathrm{SD}$ of the mean on between 5 and 7 of the 10 measures suggests low effort is not a likely explanation for the performance deficits seen among the study participants.

It is important to note that the significant correlations between difficulties reported on the FHQ and performance on the behavioral measures have face validity. That is, the association between one's score on the Woodcock Johnson Story Recall and reported problems following a series of spoken instructions is understandable, as are the associations between working memory (DS) and problems following long conversations, between performance on the TCST and needing more time than others to process spoken information, and between performance on the SSW and problems understanding when looking at the person who is speaking.

\section{STUDY LIMITATIONS}

This study has at least four limitations worthy of mention. First, there was no control group against which to compare reported and performance data, i.e., there were no data collected from a group of Veterans without blast exposure. This is because the primary study was an RCT comparing interventions for auditory difficulties associated with blast-exposure (results to be published elsewhere). Instead, the data here are compared with performance reported by others in peer-reviewed publications that examined populations of different ages, hearing levels, and demographics. While this is a weakness, it is reassuring to know that the findings here are very similar to those of Gallun et al., who examined a similar blastexposed Veteran population [18]. Second, there were no performance or behavioral assessments conducted prior to blast-exposure; thus, it is not possible to know whether the performance deficits measured here were present before military service. We are fairly confident that a preexisting deficit does not explain the findings for two reasons: participants were not eligible to participate in the study if they reported having had reading and/or learning difficulties in school and participants were asked about hearing, tinnitus, and memory problems pre- and postdeployment. 
We saw that while 79 percent reported hearing loss, 92 percent reported problems hearing in noise, 83 percent reported tinnitus, and 77 percent reported memory problems at the time of study participation, only $6,15,14$, and 7 percent, respectively, reported such problems prior to deployment. Third, study inclusion relied on self-reported blast exposure and could not be verified. Similarly, head injury at time of the blast was also by self-report, and while the presence or absence of a TBI diagnosis was extracted from electronic chart records, this too relied on self-report for that diagnosis. For this reason, the relationships between number and/or severity of blasts and the study measures were not examined. Fourth, there was no formal PTSD assessment completed using a validated measure. Indeed, symptoms of PTSD were present in that 71 percent of participants reported irritability, 87 percent reported sleep problems, and 77 percent reported memory problems postdeployment, in contrast to 7,5 , and 7 percent, respectively, prior to deployment. Further, 59 percent of participants had a formal diagnosis of PTSD in their electronic medical record, with 19 percent having a formal diagnosis of TBI. Nonetheless, the presence of PTSD does not rule out concomitant auditory processing difficulties among the participants.

In sum, the data presented here from 99 blastexposed Veterans with normal hearing sensitivity provide evidence that blast injury likely results in damage to the central auditory system. Authors of previous modeling, imaging, and behavioral studies have drawn similar conclusions [18,56-57]. Work to further understand this complex issue, including the development and assessment of rehabilitative intervention options, is necessary. To that end, the findings of an RCT comparing three interventions with standard of care will be described in a future publication.

\section{ACKNOWLEDGMENTS}

\author{
Author Contributions: \\ Study concept and design: G. H. Saunders, T. H. Chisolm, P. Myers. \\ Acquisition of data: M. T. Frederick, M. Arnold. \\ Analysis and interpretation of data: G. H. Saunders, T. H. Chisolm. \\ Drafting of manuscript: G. H. Saunders, M. T. Frederick. \\ Critical revision of manuscript for important intellectual content: \\ G. H. Saunders. \\ Statistical analysis: G. H. Saunders. \\ Obtained funding: G. H. Saunders, T. H. Chisolm, P. Myers. \\ Administrative, technical, or material support: S. Silverman. \\ Study supervision: S. Silverman.
}

Financial Disclosures: The authors have declared that no competing interests exist.

Funding/Support: This material was based on work supported by the Veterans Health Administration, Office of Research and Development, Rehabilitation Research and Development (grant C7054R).

Institutional Review: The intervention RCT study was approved by the Institutional Review Boards and the Research and Development Committees at VA Portland Health Care System and James A. Haley Veterans' Hospital, and each participant signed informed consent. Participant Follow-Up: The authors do not plan to inform participants of the publication of this study.

Disclaimer: The views expressed in this article are those of the authors and do not necessarily reflect the position or policy of the VA or U.S. Government.

\section{REFERENCES}

1. Murray CK, Reynolds JC, Schroeder JM, Harrison MB, Evans OM, Hospenthal DR. Spectrum of care provided at an echelon II medical unit during Operation Iraqi Freedom. Mil Med. 2005;170(6):516-20. [PMID:16001604]

2. Owens BD, Kragh JF Jr, Wenke JC, Macaitis J, Wade CE, Holcomb JB. Combat wounds in Operation Iraqi Freedom and Operation Enduring Freedom. J Trauma. 2008;64(2): 295-99. [PMID:18301189] http://dx.doi.org/10.1097/TA.0b013e318163b875

3. Eskridge SL, Macera CA, Galarneau MR, Holbrook TL, Woodruff SI, MacGregor AJ, Morton DJ, Shaffer RA. Injuries from combat explosions in Iraq: Injury type, location, and severity. Injury. 2012;43(10):1678-82.

[PMID:22769977]

http://dx.doi.org/10.1016/j.injury.2012.05.027

4. Chan RK, Siller-Jackson A, Verrett AJ, Wu J, Hale RG. Ten years of war: A characterization of craniomaxillofacial injuries incurred during Operations Enduring Freedom and Iraqi Freedom. J Trauma Acute Care Surg. 2012;73(6 Suppl 5):S453-58. [PMID:23192069]

http://dx.doi.org/10.1097/TA.0b013e3182754868

5. MacGregor AJ, Shaffer RA, Dougherty AL, Galarneau MR, Raman R, Baker DG, Lindsay SP, Golomb BA, Corson KS. Prevalence and psychological correlates of traumatic brain injury in Operation Iraqi Freedom. J Head Trauma Rehabil. 2010;25(1):1-8. [PMID:20051901] http://dx.doi.org/10.1097/HTR.0b013e3181c2993d

6. Okie S. Traumatic brain injury in the war zone. N Engl J Med. 2005;352(20):2043-47. [PMID:15901856] http://dx.doi.org/10.1056/NEJMp058102

7. Post-deployment healthcare challenges [Internet]. Washington (DC): Department of Veterans Affairs Office of Research and Development, Human Services Research and Development Quality Enhancement Research Initiative; 2014 Jun. 
Available from: http://www.queri.research.va.gov/about/ impact updates/PT-BRI.pdf

8. U.S. Institute of Medicine. Gulf War and health: Long-term effects of blast exposures. Washington (DC): National Academies Press; 2014.

9. Fischer H. A guide to U.S. military casualty statistics: Operation New Dawn, Operation Iraqi Freedom, and Operation Enduring Freedom. Congressional Research Service. 2014 Feb 19.

10. Schneiderman AI, Braver ER, Kang HK. Understanding sequelae of injury mechanisms and mild traumatic brain injury incurred during the conflicts in Iraq and Afghanistan: Persistent postconcussive symptoms and posttraumatic stress disorder. Am J Epidemiol. 2008;167(12): 1446-52. [PMID:18424429] http://dx.doi.org/10.1093/aje/kwn068

11. Vander Werff KR. Auditory dysfunction among long-term consequences of mild traumatic brain injury (mTBI). Perspect Hear Hear Disord Res Res Diagn. 2012;16(1):3-17.

12. Lew HL, Jerger JF, Guillory SB, Henry JA. Auditory dysfunction in traumatic brain injury. J Rehabil Res Dev. 2007;44(7):921-28. [PMID:18075949]

http://dx.doi.org/10.1682/JRRD.2007.09.0140

13. Oleksiak M, Smith BM, St Andre JR, Caughlan CM, Steiner M. Audiological issues and hearing loss among Veterans with mild traumatic brain injury. J Rehabil Res Dev. 2012;49(7):995-1004. [PMID:23341275] http://dx.doi.org/10.1682/JRRD.2011.01.0001

14. Saunders GH, Echt KV. Blast exposure and dual sensory impairment: An evidence review and integrated rehabilitation approach. J Rehabil Res Dev. 2012;49(7):1043-58.

[PMID:23341278]

http://dx.doi.org/10.1682/JRRD.2010.08.0157

15. Belanger HG, Proctor-Weber Z, Kretzmer T, Kim M, French LM, Vanderploeg RD. Symptom complaints following reports of blast versus non-blast mild TBI: Does mechanism of injury matter? Clin Neuropsychol. 2011; 25(5):702-15. [PMID:21512958] http://dx.doi.org/10.1080/13854046.2011.566892

16. Macera CA, Aralis HJ, Macgregor AJ, Rauh MJ, Galarneau MR. Postdeployment symptom changes and traumatic brain injury and/or posttraumatic stress disorder in men. J Rehabil Res Dev. 2012;49(8):1197-1208.

[PMID:23341312] http://dx.doi.org/10.1682/JRRD.2011.07.0131

17. Fausti SA, Wilmington DJ, Gallun FJ, Myers PJ, Henry JA. Auditory and vestibular dysfunction associated with blastrelated traumatic brain injury. J Rehabil Res Dev. 2009;46(6):797-810. [PMID:20104403] http://dx.doi.org/10.1682/JRRD.2008.09.0118

18. Gallun FJ, Diedesch AC, Kubli LR, Walden TC, Folmer RL, Lewis MS, McDermott DJ, Fausti SA, Leek MR. Per- formance on tests of central auditory processing by individuals exposed to high-intensity blasts. J Rehabil Res Dev. 2012;49(7):1005-25. [PMID:23341276]

http://dx.doi.org/10.1682/JRRD.2012.03.0038

19. Peru A, Beltramello A, Moro V, Sattibaldi L, Berlucchi G. Temporary and permanent signs of interhemispheric disconnection after traumatic brain injury. Neuropsychologia. 2003;41(5):634-43. [PMID:12559156] http://dx.doi.org/10.1016/S0028-3932(02)00203-8

20. Rodriguez-Paez AC, Brunschwig JP, Bramlett HM. Light and electron microscopic assessment of progressive atrophy following moderate traumatic brain injury in the rat. Acta Neuropathol. 2005;109(6):603-16. [PMID:15877231] http://dx.doi.org/10.1007/s00401-005-1010-z

21. Killion MC, Niquette PA, Gudmundsen GI, Revit LJ, Banerjee S. Development of a quick speech-in-noise test for measuring signal-to-noise ratio loss in normal-hearing and hearing-impaired listeners. J Acoust Soc Am. 2004; 116(4 Pt 1):2395-2405. [PMID:15532670] http://dx.doi.org/10.1121/1.1784440

22. Musiek FE, Shinn JB, Jirsa R, Bamiou DE, Baran JA, Zaida E. GIN (Gaps-In-Noise) test performance in subjects with confirmed central auditory nervous system involvement. Ear Hear. 2005;26(6):608-18. [PMID:16377996] http://dx.doi.org/10.1097/01.aud.0000188069.80699.41

23. Wilson RH, Moncrieff DW, Townsend EA, Pillion AL. Development of a $500-\mathrm{Hz}$ masking-level difference protocol for clinic use. J Am Acad Audiol. 2003;14(1):1-8. [PMID:12833923] http://dx.doi.org/10.3766/jaaa.14.1.2

24. Jerger J, Brown D, Smith S. Effect of peripheral hearing loss on the masking level difference. Arch Otolaryngol. 1984;110(5):290-96. [PMID:6712516] http://dx.doi.org/10.1001/archotol.1984.00800310014003

25. Musiek FE. Assessment of central auditory dysfunction: The dichotic digit test revisited. Ear Hear. 1983;4(2):79-83. [PMID:6840415] http://dx.doi.org/10.1097/00003446-198303000-00002

26. Musiek FE, Pinheiro ML. Frequency patterns in cochlear, brainstem, and cerebral lesions. Audiology. 1987;26(2):79-88. [PMID:3606474] http://dx.doi.org/10.3109/00206098709078409

27. Gatehouse S, Noble W. The Speech, Spatial and Qualities of Hearing Scale (SSQ). Int J Audiol. 2004;43(2):85-99. [PMID:15035561] http://dx.doi.org/10.1080/14992020400050014

28. Nilsson M, Soli SD, Sullivan JA. Development of the Hearing in Noise Test for the measurement of speech reception thresholds in quiet and in noise. J Acoust Soc Am. 1994;95(2):1085-99. [PMID:8132902] http://dx.doi.org/10.1121/1.408469 
29. Cameron S, Brown D, Keith R, Martin J, Watson C, Dillon H. Development of the North American Listening in Spatialized Noise-Sentences test (NA LiSN-S): Sentence equivalence, normative data, and test-retest reliability studies. J Am Acad Audiol. 2009;20(2):128-46. [PMID:19927676] http://dx.doi.org/10.3766/jaaa.20.2.6

30. Lister JJ, Roberts RA, Shackelford J, Rogers CL. An adaptive clinical test of temporal resolution. Am J Audiol. 2006; 15(2):133-40. [PMID:17182878] http://dx.doi.org/10.1044/1059-0889(2006/017)

31. Lister JJ, Roberts RA, Krause JC, Debiase D, Carlson H. An adaptive clinical test of temporal resolution: Withinchannel and across-channel gap detection. Int J Audiol. 2011;50(6):375-84. [PMID:21303227] http://dx.doi.org/10.3109/14992027.2010.551217

32. Formby C, Gerber MJ, Sherlock LP, Magder LS. Evidence for an across-frequency, between-channel process in asymptotic monaural temporal gap detection. J Acoust Soc Am. 1998;103(6):3554-60. [PMID:9637037] http://dx.doi.org/10.1121/1.423084

33. Grose JH, Hall JW 3rd, Buss E, Hatch D. Gap detection for similar and dissimilar gap markers. J Acoust Soc Am. 2001;109(4):1587-95. [PMID:11325129] http://dx.doi.org/10.1121/1.1354983

34. Vaughan N, Storzbach D, Furukawa I. Sequencing versus nonsequencing working memory in understanding of rapid speech by older listeners. J Am Acad Audiol. 2006; 17(7):506-18. [PMID:16927515] http://dx.doi.org/10.3766/jaaa.17.7.6

35. IEEE Audio and Electroacoustics Group. IEEE recommended practice for speech quality measurements. IEEE Trans Audio Electroacoust. 1969;17(3):225-46. http://dx.doi.org/10.1109/TAU.1969.1162058

36. Katz J. SSW test manual. 5th ed. Vancouver (WA): Precision Acoustics; 1998.

37. Psychological Corporation. WAIS-III, Weschler Adult Intelligence Scale, third edition: WMS-III, Weschler Memory Scale, third edition: Technical manual. San Antonio (TX): Psychological Corporation; 1997.

38. Mather M, Woodcock RW. Examiner's manual. Woodcock Johnson III Tests of Achievement. Itasca (IL): Riverside Publishing; 2001.

39. Golden CJ, Freshwater S. Stroop Color and Word Test: A manual for clinical and experimental uses. Chicago (IL): Stoelting; 2002.

40. American Speech-Language-Hearing-Association. Guidelines for manual pure-tone threshold audiometry [Internet]. Rockville (MD): ASHA; 2005. Available from: http://www.asha.org/policy/GL2005$\underline{00014 . h t m \# \text { ga=1.263933576.580987629.1430846196 }}$
41. Harris PA, Taylor R, Thielke R, Payne J, Gonzalez N, Conde JG. Research electronic data capture (REDCap) - A metadata-driven methodology and workflow process for providing translational research informatics support. J Biomed Inform. 2009;42(2):377-81. [PMID:18929686] http://dx.doi.org/10.1016/j.jbi.2008.08.010

42. Banh J, Singh G, Pichora-Fuller MK. Age affects responses on the Speech, Spatial, and Qualities of Hearing Scale (SSQ) by adults with minimal audiometric loss. J Am Acad Audiol. 2012;23(2):81-91, quiz 139-40. [PMID:22353676]

43. Brown DK, Cameron S, Martin JS, Watson C, Dillon H. The North American Listening in Spatialized NoiseSentences test (NA LiSN-S): Normative data and test-retest reliability studies for adolescents and young adults. J Am Acad Audiol. 2010;21(10):629-41. [PMID:21376004] http://dx.doi.org/10.3766/jaaa.21.10.3

44. House Ear Institute. HINT for Windows 6.1 user guide. Los Angeles (CA): Maico Diagnostics/House Ear Institute; 2001.

45. Cameron S, Dillon H, Newall P. The listening in spatialized noise test: An auditory processing disorder study. J Am Acad Audiol. 2006;17(5):306-20. [PMID:16796298] http://dx.doi.org/10.3766/jaaa.17.5.2

46. Lister JJ, Roberts RA, Lister FL. An adaptive clinical test of temporal resolution: Age effects. Int J Audiol. 2011; 50(6):367-74. [PMID:21299377] http://dx.doi.org/10.3109/14992027.2010.551218

47. Lister JJ, Koehnke JD, Besing JM. Binaural gap duration discrimination in listeners with impaired hearing and normal hearing. Ear Hear. 2000;21(2):141-50.

[PMID:10777021]

http://dx.doi.org/10.1097/00003446-200004000-00008

48. Lister JJ, Roberts RA. Effects of age and hearing loss on gap detection and the precedence effect: Narrow-band stimuli. J Speech Lang Hear Res. 2005;48(2):482-93. [PMID:15989406]

49. Zendel BR, Alain C. Musicians experience less age-related decline in central auditory processing. Psychol Aging. 2012;27(2):410-17. [PMID:21910546] http://dx.doi.org/10.1037/a0024816

50. Reynolds CR. Forward and backward memory span should not be combined for clinical analysis. Arch Clin Neuropsychol. 1997;12(1):29-40. [PMID:14588432]

http://dx.doi.org/10.1093/arclin/12.1.29

51. Wilde NJ, Strauss E, Tulsky DS. Memory span on the Wechsler Scales. J Clin Exp Neuropsychol. 2004;26(4): 539-49. [PMID:15512941] http://dx.doi.org/10.1080/13803390490496605

52. Mittenberg W, Patton C, Canyock EM, Condit DC. Base rates of malingering and symptom exaggeration. J Clin Exp Neuropsychol. 2002;24(8):1094-1102. [PMID:12650234] http://dx.doi.org/10.1076/jcen.24.8.1094.8379 
53. Lange RT, Pancholi S, Bhagwat A, Anderson-Barnes V, French LM. Influence of poor effort on neuropsychological test performance in U.S. military personnel following mild traumatic brain injury. J Clin Exp Neuropsychol. 2012; 34(5):453-66. [PMID:22273465] http://dx.doi.org/10.1080/13803395.2011.648175

54. Meyers JE, Volbrecht M, Axelrod BN, Reinsch-Boothby L. Embedded symptom validity tests and overall neuropsychological test performance. Arch Clin Neuropsychol. 2011;26(1):8-15. [PMID:21242283] http://dx.doi.org/10.1093/arclin/acq083

55. Lange RT, Brickell T, French LM, Ivins B, Bhagwat A, Pancholi S, Iverson GL. Risk factors for postconcussion symptom reporting after traumatic brain injury in U.S. military service members. J Neurotrauma. 2013;30(4):237-46. [PMID:23126461] http://dx.doi.org/10.1089/neu.2012.2685

56. Povlishock JT, Katz DI. Update of neuropathology and neurological recovery after traumatic brain injury. J Head Trauma Rehabil. 2005;20(1):76-94. [PMID:15668572] http://dx.doi.org/10.1097/00001199-200501000-00008
57. Taber KH, Warden DL, Hurley RA. Blast-related traumatic brain injury: What is known? J Neuropsychiatry Clin Neurosci. 2006;18(2):141-45. [PMID:16720789]

Submitted for publication November 3, 2014. Accepted in revised form February 12, 2015.

This article and any supplementary material should be cited as follows:

Saunders GH, Frederick MT, Arnold M, Silverman S, Chisolm TH, Myers P. Auditory difficulties in blastexposed Veterans with clinically normal hearing. J Rehabil Res Dev. 2015;52(3):343-60.

http://dx.doi.org/10.1682/JRRD.2014.11.0275

ResearcherID: Gabrielle H. Saunders, PhD: F-47682012; Melissa T. Frederick, AuD: F-2772-2015

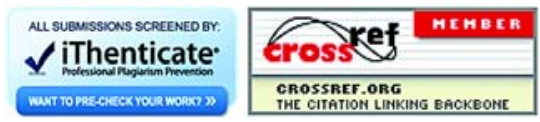


